\title{
Hardfacing of AISI 1020 Steel by Arc Welding in Comparison with TIG Welding Processes
}

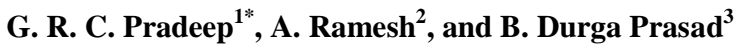 \\ ${ }^{1}$ Deparrtment of Mechanical Engineering, JNTUA, Anantapur, India \\ ${ }^{2}$ Gates Institute of Technology, Gootyanantapuram (Vill), Gooty, Anantapur, India \\ ${ }^{3}$ Department of Mechanical Engineering JNTUCEA, Anantapur, India
}

Received 18 September 2012, accepted in final revised form 11 December 2012

\begin{abstract}
Hardfacing techniques are used for enhancing the life of various machine parts by rebuilding the worn out or eroded or corroded areas in them. In this paper, an attempt has been made to determine the better welding process to hardface AISI 1020 steel based on study of wear and other factors. Two types of welding processes - Arc welding and tungsten inert gas welding (TIG) have been compared. The study revealed that the specimens prepared using TIG welding process yielded better wear properties compared to the specimen prepared using Arc welding process till $1.256 \mathrm{~m} / \mathrm{s}$ sliding velocity. Also it was observed that the Arc welding process yielded better wear properties for sliding velocities above $1.571 \mathrm{~m} / \mathrm{s}$. An attempt was made to study the reasons for getting the said results.
\end{abstract}

Keywords: Hardfacing; Arc welding; TIG welding; AISI 1020; Wear resistance.

() 2013 JSR Publications. ISSN: 2070-0237 (Print); 2070-0245 (Online). All rights reserved.

doi: http://dx.doi.org/10.3329/jsr.v5i1.11899 $\quad$ J. Sci. Res. 5 (1), 119-126 (2013)

\section{Introduction}

Hardfacing is the process of depositing of metal by means of welding process to resist wear, erosion, corrosion, high temperature, or impact. Welding technically fulfils these requirements [1]. Welding deposits extend the service life of the components [2]. Such deposition can be done anywhere on the surface subjected to wear [3]. In hard-faced component the base material contributes to the strength, and hard-facing deposition contributes to the resisting of wearing conditions to which the part will be subjected during service. Hardfacing can be done for a new part also while producing it and also for

\footnotetext{
*Corresponding author: grcpradeep@gmail.com
} 
worn out part to re-establish the worn out portion. Thus hard-facing has capability to enhance service life of a part and there by extend life of equipment [1].

Hardfacing is primarily done to improve the surface properties of the base metal [4]. For example the main components of a crusher are subjected to heavy wear and hence require good surface protection to avoid sudden break downs and also reduce the expenditure that may incur for replacement [1].This process is widely used in major manufacturing areas of power, mining, steel, cement, sugar cane, food, petro-chemicals etc, [1]. Hardfacing by welding is developing rapidly and is applied in various industries, e.g., agriculture machines, nuclear and steam power plants, pressure vessels, chemical and fertilizer plants, and even in railways, aircraft and missile components [5].

\section{Hardfacing Processes Used}

A number of welding processes can be used for hardfacing. The selection of the most suitable welding process for a given component depends on a number of factors [3] like: Base metal composition, Function of the component, Nature of work to which the component to be hard-faced is subjected to, Accessibility of weld equipment, State of repair of worn components, Size and shape of component, Number of same or similar items to be hard-faced and cost of replacement of the part etc. There are various processes for hardfacing. The following processes are compared in the present study:

- Hardfacing by arc welding - Shielded metal arc welding (SMAW) [6].

- Hardfacing by combination of arc and gas - Tungsten inert gas welding (TIG) [7].

\section{Base Material and Weld Consumable Used in Hardfacing}

Almost $85 \%$ of the metal produced and used in majority applications is steel. AISI series C-1008 to C-1020, 2315, 2515, and 2517 [8-11] includes the low-carbon steels and lowalloy steels used for making various components for diverse applications. These steel series generally have, Carbon ranging from 0.10 to $0.25 \%$, manganese ranging from 0.25 to $1.5 \%$, phosphorous of $0.4 \%$ maximum, and sulfur of $0.5 \%$ maximum. These steels can be easily welded with any of the welding processes like Arc welding, TIG welding, Resistance welding etc. In the present study the base material and weld consumable used are AISI 1020 steel. This was done to know the effect of different welding process on wear of hard-faced components.

\section{Sample Preparation and Testing}

The material used for the sample preparation is AISI 1020 steel. The chemical composition, physical and mechanical properties of the material are given below: 
Table 1 . Chemical composition of AISI 1020 steel by wt $\%$.

\begin{tabular}{lccccc}
\hline Element & $\mathrm{C}$ & $\mathrm{Mn}$ & $\mathrm{P}$ & $\mathrm{S}$ & $\mathrm{Fe}$ \\
\hline Composition (\%) & $0.18-0.23$ & $0.30-0.60$ & 0.04 (Max) & 0.05 (Max) & Balance \\
\hline
\end{tabular}

Table 2. Physical and mechanical properties of AISI 1020 steel.

\begin{tabular}{lccccc}
\hline Property & $\begin{array}{c}\text { Elastic modulus } \\
(\mathrm{GPa})\end{array}$ & $\begin{array}{c}\text { Density } \\
\left(\times 10^{3} \mathrm{~kg} / \mathrm{m}^{3}\right)\end{array}$ & Poisson's ratio & $\begin{array}{c}\text { Hardness } \\
(\mathrm{HB})\end{array}$ & $\begin{array}{c}\text { Tensile strength } \\
(\mathrm{MPa})\end{array}$ \\
\hline Value & $190-210$ & $7.7-8.03$ & $0.27-0.30$ & 111 & 394.7 \\
\hline
\end{tabular}

Preparation of test samples was done as per ASTM standards. Round rods of AISI 1020 steel of $10 \mathrm{~mm}$ diameter are taken and cut in to required lengths. Thorough cleaning was done to remove oil and dirt. Burr is removed from the faces and finished to maintain flat surfaces. AISI 1020 material is deposited on the flat face of each sample by welding using two different methods namely, Arc welding and TIG welding (with Argon as inert gas). Smooth cylindrical finish and size required as per ASTM standards was obtained in turning with fine cuts. The samples are by held in drilling machine and rubbed on sand belt machine so that their faces are smooth finished, for perfect contact to test on POD machine. At least $5 \mathrm{~mm}$ height of the weld deposit was maintained in the total sample length as shown in Fig. 1. Computerized Pin on Disc wear testing Machine with the sample as test material and high carbon EN31 steel (HRC 60) as counter-surface equipped with LVDT and digital display system was used to record the wear height loss.

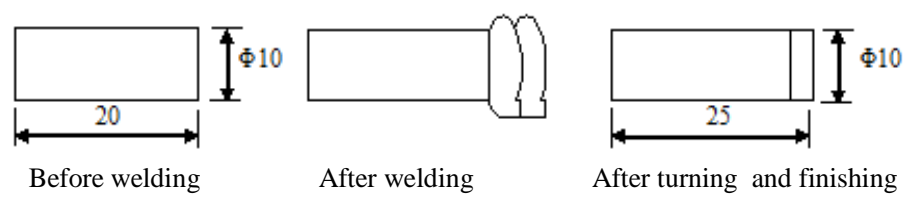

Fig. 1. Steps in sample preparation.

\section{Results and Discussion}

The plain sample without welding, Arc welded sample and TIG welded sample are tested on the POD machine to find out the wear characteristics at different sliding distances and different loads. The sliding velocities used for the test are $0.9426 \mathrm{~m} / \mathrm{s}, 1.256 \mathrm{~m} / \mathrm{s}, 1.571$ $\mathrm{m} / \mathrm{s}$. The load was varied in steps of $9.81 \mathrm{~N}$ from $9.81 \mathrm{~N}$ to $49.05 \mathrm{~N}$. Each sample was tested in steps of $94.26 \mathrm{~m}$ for different sliding distances from $282.78 \mathrm{~m}$ to $2827.8 \mathrm{~m}$. Calculation of wear volume, wear factor and frictional coefficient is done taking the average of 8 readings and used for plotting the graphs. Figs. 2(a) to 2(c), 3(a) to 3(c), 4(a) to 4(c) show the sample of the graphs obtained for a particular sliding velocity and load. 


\subsection{Effect on wear volume}

It can be seen from Fig. 2(a) to Fig. 2(c) that the values of wear volume for plain sample without welding (base metal) and the Arc welded sample are very close, at sliding velocity of $0.9426 \mathrm{~m} / \mathrm{s}$. For the same sliding velocity, TIG welding sample was showing better wear properties. At higher sliding velocities above $1.256 \mathrm{~m} / \mathrm{s}$ it was seen that the values of Arc welding sample and TIG welding sample are very close. However TIG welding sample was showing better wear properties at such velocity. The reason for this may be because of \% Dilution being less in TIG Welding and also may be due to the high hardness of the narrow heat affected zone thus resulting in enhanced wear properties at lower sliding velocities. However it was observed that the wear properties of Arc welded samples at still higher sliding velocities of $1.571 \mathrm{~m} / \mathrm{s}$ were enhanced compared to TIG welding samples. This may be due to higher hardness of broader heat affected zone in Arc welding. At higher velocities, the narrow heat affected zone in TIG welding might have reduced the resistance to wear, as the metal peels out in the form of chips due to the higher heat generation at higher sliding velocities and higher loads.

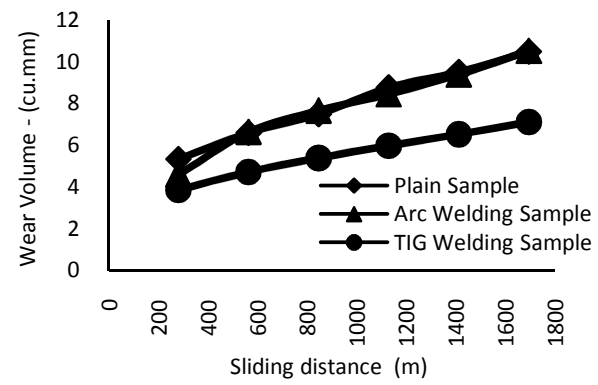

Fig. 2 (a). Wear vol vs sliding dist at $0.9426 \mathrm{~m} / \mathrm{s}$ sliding velocity and $49.05 \mathrm{~N}$ load.

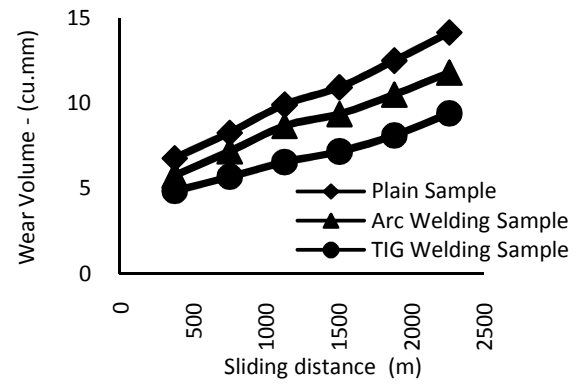

Flg. 2 (b). Wear vol vs sliding dist at $1.256 \mathrm{~m} / \mathrm{s}$ sliding velocity and $49.05 \mathrm{~N}$ load.

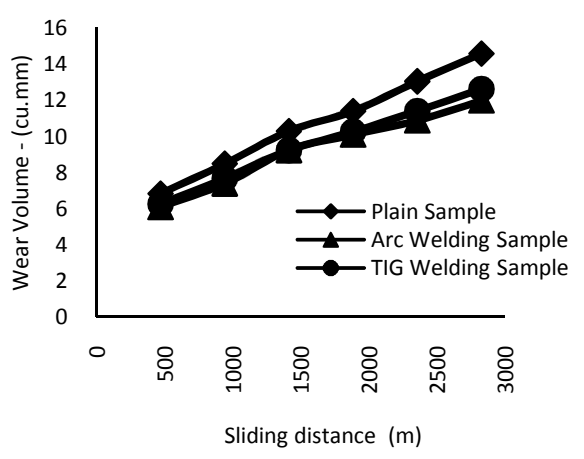

Fig. 2 (c). Wear vol vs sliding dist at $1.571 \mathrm{~m} / \mathrm{s}$ sliding velocity and $49.05 \mathrm{~N}$ load. 


\subsection{Effect on wear factor}

It can be seen from Fig. 3(a) to Fig. 3(c) that at sliding velocity of $0.9426 \mathrm{~m} / \mathrm{s}$, the values of the wear factor for TIG welding sample were better than Arc welded sample. At higher sliding velocities above $1.256 \mathrm{~m} / \mathrm{s}$ the wear factor values of Arc welding sample and TIG welding sample were observed to be very close, but TIG welding sample was showing better values. Also it can be seen that the Wear Factor values of Arc welded samples were enhanced compared to TIG welding samples at still higher sliding velocities of $1.571 \mathrm{~m} / \mathrm{s}$.

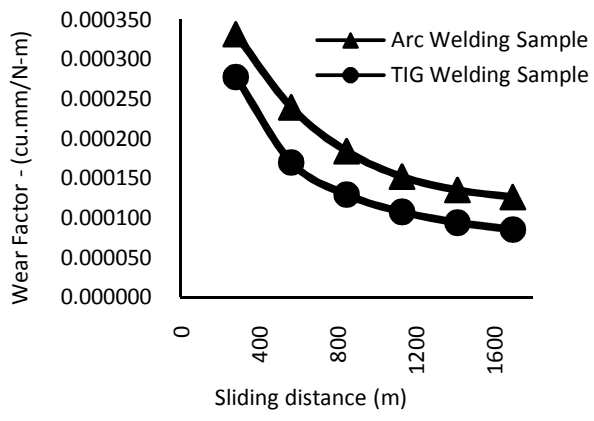

Fig. 3 (a). Wear factor vs sliding dist at $0.9426 \mathrm{~m} / \mathrm{s}$ sliding velocity and $49.05 \mathrm{~N}$ load.

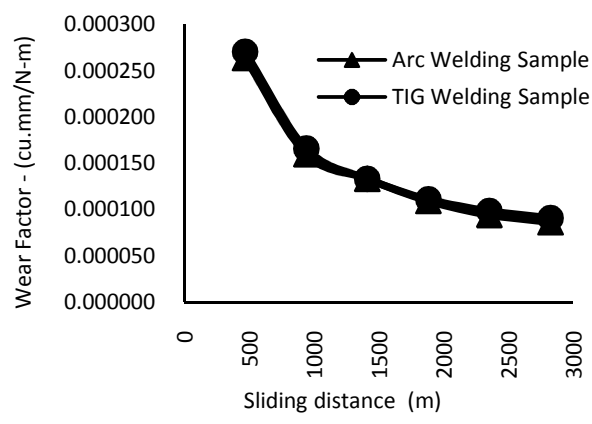

Fig. 3 (c). Wear factor vs sliding dist at $1.571 \mathrm{~m} / \mathrm{s}$ sliding velocity and $49.05 \mathrm{~N}$ load.

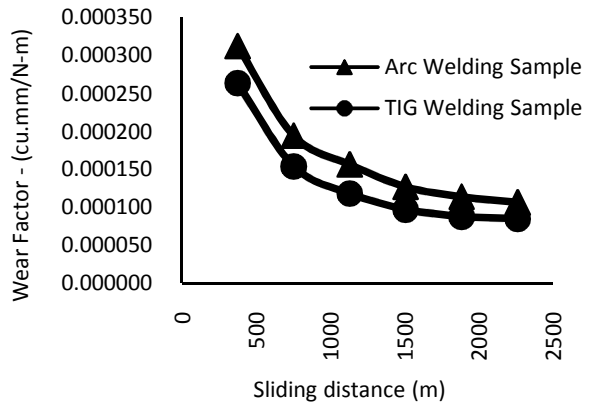

Fig. 3 (b). Wear factor vs sliding dist at $1.256 \mathrm{~m} / \mathrm{s}$ sliding velocity and $49.05 \mathrm{~N}$ load.

\subsection{Effect on friction coefficient}

It can be seen for Fig. 4(a) to Fig. 4(c) that at sliding velocity of $0.9426 \mathrm{~m} / \mathrm{s}$, the values of the friction coefficient for TIG welding sample were higher than Arc welded sample. At higher sliding velocities above $1.256 \mathrm{~m} / \mathrm{s}$ the friction coefficient values of Arc welding sample and TIG welding sample were observed to be very close, but TIG welding sample was showing better values. Also it can be seen that the friction coefficient values of Arc welded samples were enhanced compared to TIG welding samples at still higher sliding velocities of $1.571 \mathrm{~m} / \mathrm{s}$. 


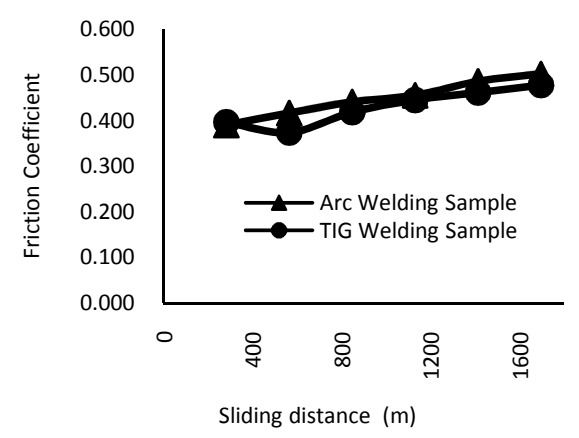

Fig. 4 (a). Friction coeff vs sliding dist at 0.9426 $\mathrm{m} / \mathrm{s}$ sliding velocity and $49.05 \mathrm{~N}$ load.

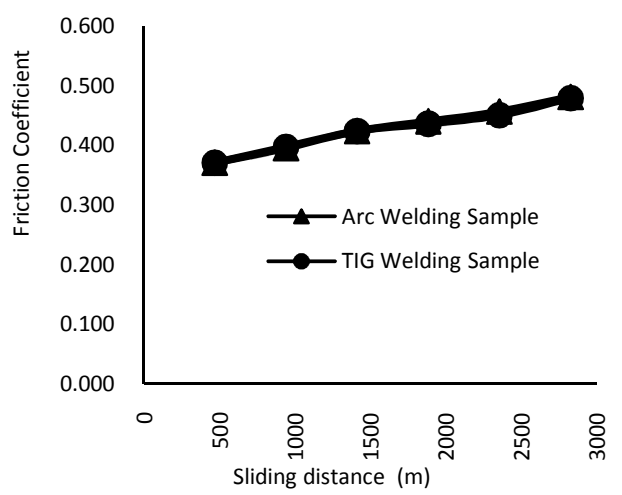

Fig. 4 (c). Friction coeff vs sliding dist at $1.571 \mathrm{~m} / \mathrm{s}$ sliding velocity and $49.05 \mathrm{~N}$ load.

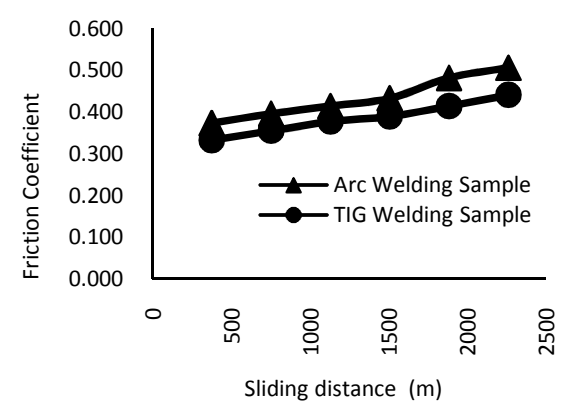

Fig. 4 (b). Friction coeff vs sliding dist at $1.256 \mathrm{~m} / \mathrm{s}$ sliding velocity and $49.05 \mathrm{~N}$ load.

\subsection{SEM micro photographs}

The nature of the wear surface of the welded samples was studied by using Scanning Electron Microscopy, which is one of the conventional characterization techniques. Micro photographs at 50x, 200x, 400x magnifications were taken. Few sample photographs are shown in Figs. 5(a), Fig. 5(b). It can be observed from Figs. that that TIG welding sample has better wear properties compared to Arc welded sample at higher Sliding Velocities above $1.256 \mathrm{~m} / \mathrm{s}$ as the Arc welding sample shows deeper plough marks and TIG welding sample shows small chips and particles. However TIG welding samples show deeper plough marks with delamination compared to Arc welded samples at still higher sliding velocities of $1.571 \mathrm{~m} / \mathrm{s}$. Hence the wear properties of Arc welded samples at higher sliding velocities of $1.571 \mathrm{~m} / \mathrm{s}$ were seen enhanced compared to TIG welding samples. Hence the SEM microphotographs also support the discussion in the previous sections. 

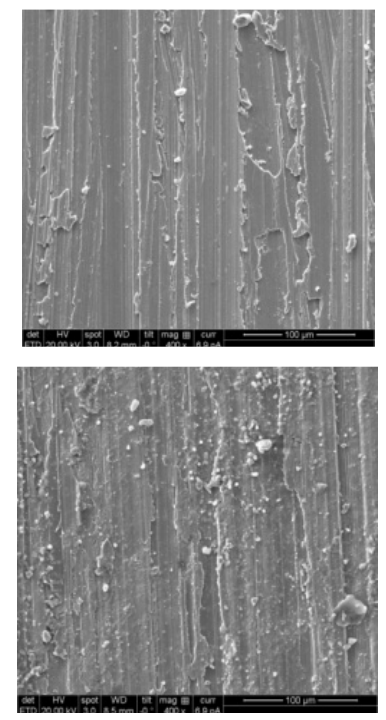

Fig. 5(a). SEM micro photograph at 400x magnification (i) Arc weld sample, (ii) TIG weld sample at $1.256 \mathrm{~m} / \mathrm{s}$ sliding velocity and load $49.05 \mathrm{~N}$.
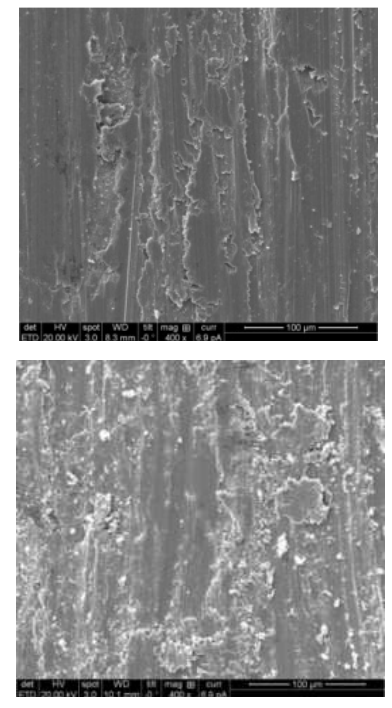

Fig. 5(b). SEM micro photograph at 400x magnification (i) Arc weld sample, (ii) TIG weld sample at $1.571 \mathrm{~m} / \mathrm{s}$ sliding velocity and load $49.05 \mathrm{~N}$.

\subsection{Result agreement with earlier researchers}

The earlier researchers [12] who have compared different welding processes using AHP (Analytic hierarchy process model) based on quantitative and qualitative factors concluded that the integrated process measure (PM) for TIG welding was 0.2150 among the different processes to hardface carbon steels. The value of integrated process measure for Arc welding was 0.1385 and other processes are still lesser except PTAW.

It was concluded by Gourd [4] that percentage dilution plays a major role in determining the properties of a hardfaced surface. Dilution is defined as the percentage of base metal in the weld metal deposit. If the percentage of dilution is low, then the percentage of base metal in the weld metal deposit will be low and vice versa. Because of the presence of a higher amount of base metal at a higher percentage of dilution level, the surface properties are not enhanced to the expected level. On other hand, at a lower percentage of dilution level, the surface properties are much better compared to the base metal because of a low percentage of base metal in the deposited weld metal. Hence, the welding process which produces a low percentage of dilution is generally preferred for hardfacing applications [13]. The dilution factors for various processes are given below [14]. 


\subsubsection{Welding process dilution factors}

TIG welding

Shielded metal Arc welding

Submerged Arc welding
$5-15 \%$ dilution

$20-45 \%$ dilution

$25-50 \%$ dilution

\section{Conclusions}

TIG welding samples show better wear properties than Arc welding samples till the sliding velocity of $1.256 \mathrm{~m} / \mathrm{s}$ with various sliding distances and loads. On the other hand Arc welding samples yield better results at higher sliding velocities above $1.571 \mathrm{~m} / \mathrm{s}$ with various sliding distances and various loads compared to TIG welded samples.

\section{References}

1. M. Kirchgaßner, E. Badisch, and F. Franek, Wear 265 (5-6), 772 (2008). http://dx.doi.org/10.1016/j.wear.2008.01.004

2. A. Gualco, H. G. Svoboda, E. S. Surian, and L. A. de Vedia, Materials \& Design 31 (9), 4165 (2010). http://dx.doi.org/10.1016/j.matdes.2010.04.026

3. G. R. C. Pradeep, A. Ramesh, B. Durga Prasad, Int. J. Eng. Sci. Tech. X, (XX), 1 (2010).

4. L. M. Gourd, Principles of welding technology (Viva Books, New Delhi, 1998).

5. L. L. Richard, Welding and welding technology (Tata McGraw-Hill, New Delhi, 1990).

6. A. C. Crespo, A. Scotti, and M. R. Pérez, J. Mater. Process. Techn. 199 (1-3), 265 (2008). http://dx.doi.org/10.1016/j.jmatprotec.2007.07.048

7. H. Kashani, A. Amadeh, and H. M. Ghasemi, Wear 262 (7-8), 800 (2007). http://dx.doi.org/10.1016/j.wear.2006.08.028

8. X. H. Wang, F. Han, X. M. Liu, S. Y. Qu, and Z. D. Zou, Mater. Sci. Eng. A, 489 (1-2), 193 (2008). http://dx.doi.org/10.1016/j.msea.2007.12.020

9. X. H. Wang, S. L. Song, Z. D. Zou, and S. Y. Qu, Mater. Sci. Eng. A, 441 (1-2), 60 (2006). http://dx.doi.org/10.1016/j.msea.2006.06.015

10. Xin-hong Wang, Fang Han, Shi-yao Qu, Zeng-da Zou, Surf. Coatings Techn. 202 (8), 1502 (2008). http://dx.doi.org/10.1016/j.surfcoat.2007.07.002

11. X. Wang, F. Han, X. Liu, S. Qu, and Z. Zou, Wear, 265 (5-6), 583 (2008). http://dx.doi.org/10.1016/j.wear.2007.12.001

12. V. Balasubramanian, R. Varahamoorthy, C. S. Ramachandran, and C. Muralidharan, Int. J. Adv. Manufac. Techn. 40, 887 (2009). http://dx.doi.org/10.1007/s00170-008-1406-8

13. K. Marimuthu and N. Murugan, Surf. Eng. 19, 143 (2003). http://dx.doi.org/10.1179/026708403225002586

14. Product Reference Manual - (AFROX - Section -12), www.afrox.co.za/en/customer_service/publications/product_reference_manual/Index.html 